\title{
Relação parasitemia e leucograma de gatos infectados com Trypanosoma evansi
}

\section{Relationship between parasitemia and leukogram in Trypanosoma evansi infected cats}

\author{
Aleksandro Schafer Silva ${ }^{1}$; Patrícia Wolkmer ${ }^{1}$; Márcio Machado Costa ${ }^{1}$; \\ Luciana Faccio ${ }^{2}$; André Vasconcelos Soares ${ }^{1}$; Érika Fernanda Garcia ${ }^{1}$; Sonia \\ Terezinha dos Anjos Lopes ${ }^{3}$; Janio Morais Santurio ${ }^{3}$; Silvia Gonzalez Monteiro ${ }^{3 *}$
}

\section{Resumo}

Trypanosoma evansi é um protozoário que causa a tripanossomose em animais de muitos países do sudeste da Ásia, África e América do Sul. Optamos por utilizar os gatos em nosso estudo, devido à facilidade de manipular os animais e a falta de estudos envolvendo a tripanossomose nesta espécie. Deste modo, o objetivo deste estudo foi investigar alterações no leucograma de felinos domésticos infectados experimentalmente por T. evansi e relacionar com a parasitemia. Foram utilizados 13 gatos, divididos em dois grupos. Sete deles foram infectados com T. evansi e o restante foram utilizados como grupo controle negativo. Os animais foram monitorados diariamente através de esfregaço sanguíneo. Nos dias $0,7,21,35$ e 49 de experimento, foram coletadas amostras de sangue para avaliação do leucograma. O pico de parasitemia ocorreu cinco dias após inoculação, após este período o número de parasitos reduziu e manteve-se com picos irregulares, variando de zero a três tripomastigotas/campo. Na pesquisa foi verificado aumento ( $\mathrm{P}<0,05)$ do número de leucócitos totais (dia 49), bastonetes (dia 35), neutrofilos segmentados (dia 49) e monócitos (dias 7, 35 e 49) e redução de linfocitos e eosinofilos (dias 21, 35 e 49). Gatos infectados com T. evansi apresentam leucocitose, neutrofilia, monocitose, linfopenia e eosinopenia. Porém, não foi verificado relação entre os picos de parasitemia e alteração no número de globulos brancos circulantes, com execção dos monócitos no dia 7.

Palavras-chave: Tripanossomose, felinos, sistema imunológico, parasitismo

\footnotetext{
Abstract

Trypanosoma evansi is a protozoan which causes trypanosomosis in livestock in many countries of Southeast Asia, Africa and South America. We chose to use cats in our study due to the facility to handle the animals and the lack of studies involving the trypanosomosis in this species. The aim of this study was to analyze the leukogram of domestic cats experimentally infected with $T$. evansi and its correlation to the parasitemia. Thirteen animals were divided into two groups. Seven animals were infected with T. evansi and six were used as negative control. Parasitemia was estimated daily by microscopic examination of smears. Blood samples for leukogram were collected at days $0,7,21,35$ and 49 . The

1 Programa de Pós-Graduação em Medicina Veterinária da Universidade Federal de Santa Maria (UFSM), Santa Maria - RS, Brasil. E-mail: aleksandro_ss@yahoo.com.br; patiwol@hotmail.com; marmvet@yahoo.com.br; decaves@bol.com.br; erikavet5@ hotmail.com

2 Bolsista de Iniciação Científica da UFSM, Santa Maria - RS, Brasil. lucianabfaccio@hotmail.com

3 Professor Adjunto do curso de Medicina Veterinária da UFSM. Faixa de Camobi - Km 9, Campus Universitário, Santa Maria RS, Brasil. 97105-900, Prédio 20, Sala 4232. Fax: (55) 3220-8958. sgmonteiro@uol.com.br; sonia@smail.ufsm.br; santurio@ smail.ufsm.br

* Autor para correspondência
} 
parasitemia peak was recorded at day five post-inoculation. Thereafter, irregular waves of parasitemia were observed, ranging from zero to three trypomastigotes per microscopic field. Increased number of total leukocytes (day 49), monocytes (days 7, 35 and 49), segmented (day 49) and nonsegmented neuthrophils (day 35), and decreased number of lymphocytes and eosinophils (days 21, 35 and 49) were observed $(\mathrm{P}<0.05)$. Cats infected with $T$. evansi have leukocytosis, neutrophilia, monocytosis, lymphopenia and eosinopenia. However, no relationship between parasitemia peaks and white blood cells was observed, except by the monocytes in day 7 .

Key words: Trypanosomosis, felines, immunological system, parasitism

\section{Introdução}

A doença causada pelo Trypanosoma evansi (Kinetoplastida: Trypanosomatidae) é comumente denominada mal das cadeiras em equinos (SILVA et al., 1995; SILVA et al., 2002). O T. evansi é um protozoário flagelado que parasita uma grande diversidade de mamíferos, em áreas de clima tropical (LUN; DESSER, 1995). Os tabanídeos e morcegos hematófagos são os responsáveis pela transmissão mecânica do parasito entre hospedeiros, com ocorrência de surtos em estações quentes (HOARE, 1972; MONZON; MANCEBO; ROUX, 1990).

A tripanossomose por $T$. evansi pode provocar anemia em graus variados, edema de membros e partes baixas, febre, letargia, perda de apetite, emagrecimento, lacrimejamento, aborto, perda de condição corporal, formações de placas cutâneas, sangramentos nasais e oculares e uma claudicação típica, que denomina a enfermidade (KUBIAK; MOLFI, 1954; SILVA et al., 1995; SILVA et al., 2002; HERRERA et al., 2004).

Em equinos, camelos, cães, coelhos e roedores a infecção por $T$. evansi leva a alterações como oscilações entre leucocitose e leucopenia, linfocitose e linfopenia durante a parasitemia (JATKAR; PUROHIT, 1971; AQUINO et al., 2002; RODRIGUES et al., 2005). No modelo felino não foi avaliado, até a presente data, o leucograma de animais infectados pelo T. evansi, assim, o presente trabalho tem como objetivo de investigar alterações no leucograma de felinos domésticos infectados experimentalmente pelo $T$. evansi, relacionando estas alterações com a parasitemia.

\section{Material e Métodos}

Para este estudo foram utilizados 13 felinos (Felis catus) adultos, fêmeas, sem raça definida. $\mathrm{O}$ peso dos gatos no início da pesquisa variou entre 1.912 e 2.561 gramas. Os animais foram mantidos em gaiolas individuais, alimentados diariamente com ração comercial e água a vontade. A temperatura e a umidade do ambiente foram mantidas constantes $\left(23^{\circ} \mathrm{C} ; 70 \% \mathrm{UR}\right)$. Os felinos passaram por um período de adaptação de 30 dias antes de iniciar o experimento, quando foram vermifugados (pamoato de pirantel, praziquantel e fenbendazole). Para avaliar se os animais estavam sadios foram realizadas três séries de exames hematológicos e bioquímicos em intervalos de 15 dias, onde foi constatado que os parâmetros avaliados estavam dentro dos valores de referência (BUSH, 2004).

Os gatos foram divididos em dois grupos, sendo um grupo controle (seis animais) e outro grupo infectado (sete animais). Os F. catus foram inoculados via intraperitonial com um isolado de T. evansi obtido de um cão naturalmente infectado (COLPO et al., 2005), mantido no laboratório em nitrogênio. A dose infectante utilizada foi de $10^{8}$ tripomastigotas por animal. No grupo controle foi administrado, pela mesma via, solução fisiológica. Após inoculação dos parasitos, a parasitemia foi monitorada diariamenteporseis diase posteriormente em intervalos de três dias durante 56 dias, através de pesquisa microscópica em esfregaço sanguíneo. As coletas foram feitas utilizando agulha hipodérmica estéril introduzida na região distal da cauda dos gatos para obtenção de uma gota de sangue. Após 
a confecção da lâmina, os esfregaços foram corados por Panótico Rápido e analisados em microscópio de luz em aumento de 1000 vezes. Foi realizado um único esfregaço por animal e a leitura foi realizada em toda a extensão do esfregaço. Quando o número de flagelados estava aumentado, a quantificação de parasitos foi realizada por campo microscópico conforme método de Da Silva, Doyle e Monteiro (2006).

O período experimental foi de 56 dias, sendo as amostras de sangue coletadas nos dias 0, 7, 21, 35 e 49. Para análise do leucograma foi coletado sangue da jugular e armazenado em tubos com ácido etilenodiaminotetracético (EDTA) a 10\%. O eritrograma também foi avaliado nas mesmas datas (DA SILVA et al., 2009). Para facilitar as coletas e reduzir o estresse da manipulação, os animais foram sedados com cetamina $\left(0,08 \mathrm{ml} \mathrm{kg}^{-1}\right)$ e xilazina $\left(0,05 \mathrm{ml} \mathrm{kg} \mathrm{kg}^{-1}\right)$. A coleta de sangue foi realizada logo após a sedação dos felinos (5 minutos após administração dos fármacos). Os grupos controle e infectado descarta qualquer alteração no leucograma em decorrência do uso anestésico, pois todos os gatos passaram pelos mesmos procedimentos e posteriormente os resultados foram comparados entre grupos.

Os parâmetros imunológicos analisados neste trabalho foram: leucócitos totais, linfócitos, neutrófilos segmentados, bastonetes, eosinófilos, basófilos e monócitos. Os esfregaços sanguíneos confeccionados de cada amostra foram corados com Panótico Rápido para a contagem diferencial e avaliação citológica. A contagem de leucócitos totais foi realizada em aparelho de contagem celular eletrônico (CELM ${ }^{\circledR}$ - mod. CC 530). A interpretação dos resultados foi realizada segundo Bush (2004). Os dados obtidos foram analisados estatisticamente através da análise de variância (ANOVA), seguida da aplicação do teste de Tukey para comparação entre as médias (SILVA; AZEVEDO, 2002).

\section{Resultados e Discussão}

Através do esfregaço sanguíneo periférico pode ser constatado que o período pré-patente em gatos infectados experimentalmente oscila entre 24 e 48 horas (Figura 1A). Em ratos Wistar, que são considerados modelos apropriados para estudos com T. evansi, o período pode variar entre 1,5 e 5,6 dias (OLIVEIRA; MENEGUIN; PEREIRA, 1989; QUEIROZ et al., 2001). Em coelhos, o período prépatente pode compreender entre 6 e 11 dias (DA SILVA et al., 2008). A diferença entre as espécies pode estar relacionada a dose de parasitos inoculada ou a imunidade dos animais frente à infecção, pois um número maior de anticorpos capacitados a destruir o T. evansi (UCHE; JONES, BOID, 1992) pode estar relacionado com a resposta do organismo frente ao parasito.

O pico de parasitemia ocorreu cinco dias após inoculação (10 a 13 tripanossomas/campo microscópico). Após este período, a parasitemia manteve picos irregulares variando de zero a três tripomastigotas/campo na maioria dos animais (Figura 1A). Resultado semelhante foi descrito por Choudhury e Misra (1972) em gatos infectados experimentalmente. Já em ratos, o aumento da parasitemia é crescente, sendo que estes animais morrem com mais de 100 tripomastigotas por campo cinco dias após inoculação (DOYLE et al., 2007). Em animais silvestres como capivara e quatis, a infecção é crônica, porém, sem sinais clínicos, o que leva pesquisadores considerarem estes hospedeiros reservatórios do parasito. Já em animais domésticos como cães, equinos e camelos, a doença tem caráter crônico com picos de parasitemia associados a sinais clínicos típicos de tripanossomose (JATKAR; PUROHIT, 1971; COLPOetal., 2005; RODRIGUES et al., 2005), semelhante ao que ocorreu em todos os gatos infectados neste estudo, que apresentaram hipertermia, hiporexia, linfodenopatia, edemaciação e caquexia. 

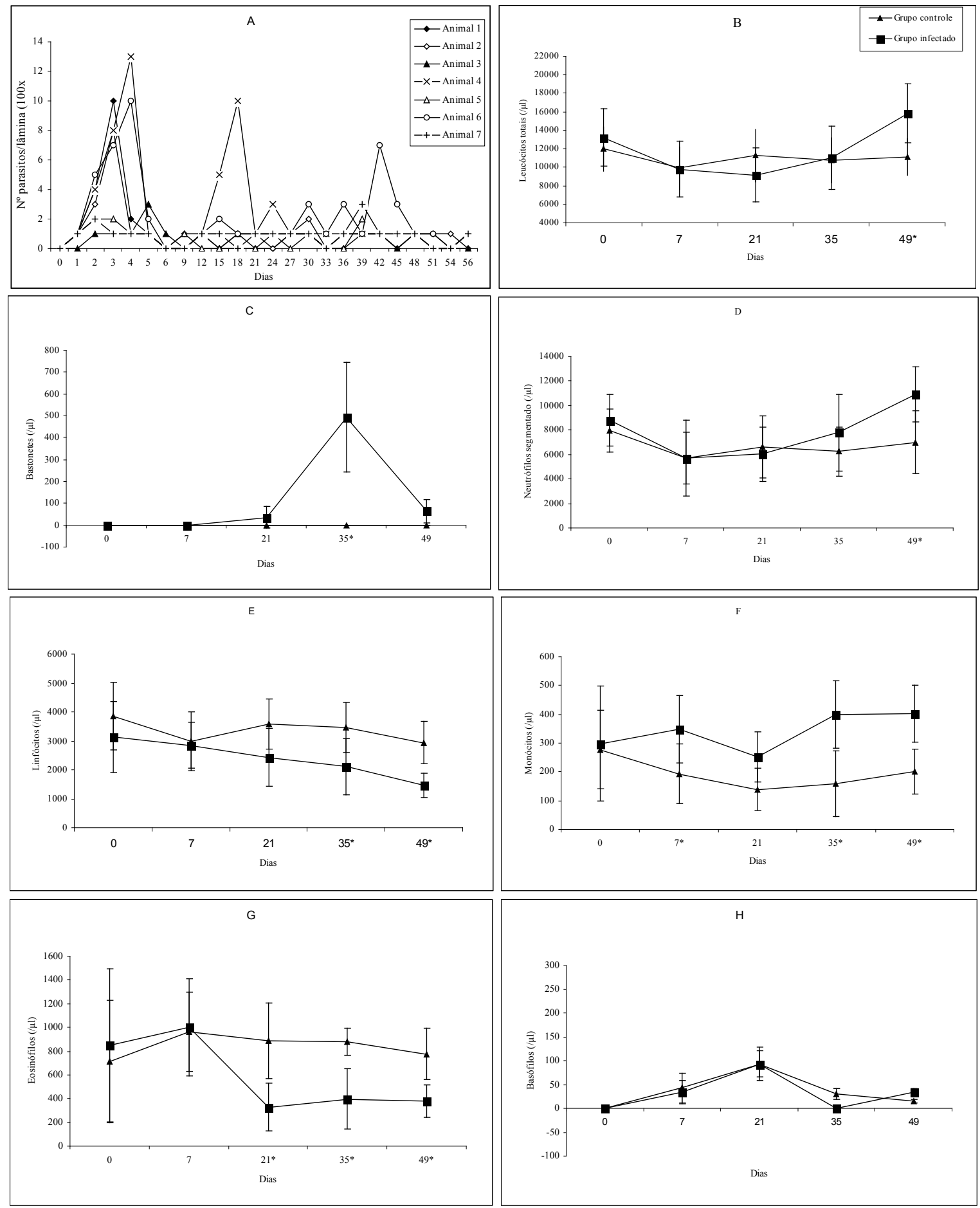

Figura 1- Gatos infectados experimentalmente com Trypanosoma evansi: (A) evolução da parasitemia; (B) Leucócitos totais; (C) Bastonetes; (D) Neutrófilos segmentados; (E) Linfócitos; (F) Monócitos; (G) Eosinófilos; (H) Basófilos. (*diferença estatística entre os grupos no teste de Tukey a 5\%). 
Quando a parasitemia foi relacionada com o leucograma, verificou-se que os monócitos foram as únicas células que alteraram-se com o aumento de tripomastigotas (dia 7) na circulação (Figura 1A-F). As demais mudanças ocorridas no leucograma no decorrer do experimento não coincidiram com aumento da parasitemia, pois o mesmo manteve-se irregular e de grau leve (Figura 1A). Na Figura 1 pode ser visualizado aumento $(\mathrm{P}<0,05)$ do número de leucócitos totais (dia 49), bastonetes (dia 35), neutrofilos segmentados (dia 49) e monócitos (dias 7,35 e 49) e redução de linfocitos e eosinofilos (dias 21, 35 e 49). Concomitantemente a estas alteraçoes, foi observado nos gatos deste estudo, redução do número de celulas vermelhas, caracterizando uma anemia crônica de grau leve (DA SILVA et al., 2009).

Os felinos apresentaram leucocitose e neutrofilia somente na última semana do experimento, demonstrando uma resposta aguda no dia 49, final da pesquisa. Essa resposta poderia estar associada ao oportunismo de outros agentes, ja que não houve mudanças na parasitemia nesse período, promovendo a mobilização desses neutrófilos para os tecidos e, assim, estimulando a medula, através de citocinas, a liberar novas células dos compartimentos medulares de maturação e reserva (FELDMAN; ZINKL; JAIN, 2000). O desvio a esquerda (pico de bastonetes) no dia 35 deixa claro que a mobilização de células imaturas na circulação foi devido a uma provável demanda tecidual em resposta inflamatória e responsiva a infecção pelo flagelado, porém não tendo relação com o número de parasitos circulante, mas sim com as alteraçoes clinicas de edema de face, emagressimento progressivo e aumento da temperatura. Cães infectados experimentalmente com T. evansi podem ter leucopenia e neutropenia (AQUINO et al. 2002) ou nao ter alteração referente ao leucograma (RUE et al., 2000). Isto mostra que o leucograma de animais infectados por T. evansi pode variar, pois cães apresentam redução dos leucocitos circulantes, enquanto os gatos apresentam aumento destas células, semelhante ao que ocorrre em cobaios e equinos (MONZON; VILLAVICENCIO; ROUX, 1991; RODRIGUES et al., 2005).

Os monócitos foram os glóbulos brancos que tiveram maior variação no decorrer do experimento (Figura 1F). Em cães infectados com o flagelado, que seriam os modelos experimentais mais próximos aos felinos, não foi reportado mudança no número de monócitos circulantes (RUE et al., 2000; AQUINO et al., 2002). O T. evansi tem tropismo pelo tecido muscular (QUIÑONES; FINOL; TORRES, 1994) em consequência disso, as células circulantes não podem combatê-lo. Os monócitos originam os macrófagos, células especializadas em destruir agentes etiológicos fora dos vasos sanguíneos. Essa afinidade do parasito pelo músculo e a presença de infiltrado inflamatório, relatado por Quiñones, Finol e Torres (1994), com predominante número de macrófagos, poderia ser uma das principais causas de monocitose. Da mesma forma, os macrófagos são indispensáveis para a resposta adquirida, pois promovem a apresentação de antígenos e produção de citocinas, auxiliando na formação da resposta específica para cada agente. Assim, a mobilização dessas células da medula óssea para a circulação de uma forma quase que contínua neste estudo, reflete a tentativa do sistema imune em combater o parasito.

A linfocitopenia e eosinopenia verificadas nos gatos não é reportada em outros estudos envolvendo carnívoros (RUE et al., 2000; AQUINO et al., 2002) e equinos parasitados por T. evansi (RODRIGUES et al., 2005; ZANETTE et al., 2008). A diminuição no número de linfócitos pode estar relacionada à deficiência de elementos essenciais para produção destas células, como exemplo ferro e zinco (SAKER, 2006), minerais estes que estão reduzidos nos casos de tripanossomose (MWANGI; MCODIMBA; LOGAN-HENFREY, 1995; GUTIERREZ et al., 2006). Também, nos casos de leishmaniose, Bush (2004) relata que a linfopenia é gerada em decorrência do confinamento temporário dos linfócitos no baço ou linfonodos, em resposta aos antígenos do protozoário ou pela destruição dos linfócitos pelo próprio agente e/ou estresse pela 
parasitemia crônica. A eosinopenia, presente neste estudo é de difícil associação a algum fenômeno patológico, pois os valores de referência nos gatos domésticos podem chegar à zero por microlitro de sangue. Uma possível causa de eosinopenia são infecções agudas ou estresse em decorrência da evolução da doença (FELDMAN; ZINKL; JAIN, 2000). Os basófilos não diferiram entre os grupos neste estudo (Figura 1H).

Os resultados permitem concluir que a tripanossomose por $T$. evansi acarreta alterações no leucograma, porém estas mudanças não estão relacionadas com os picos de parasitemia. Gatos infectados com T. evansi apresentam leucocitose, neutrofilia, monocitose, linfopenia e eosinopenia.

\section{Comitê de Bioética}

O presente experimento foi aprovado pelo Comitê deÉticae Bem-EstarAnimal da UniversidadeFederal de Santa Maria (UFSM), n²3081.002891/2008-47, de acordo com legislação vigente e os Princípios Éticos publicados pelo Colégio Brasileiro de Experimentação Animal (COBEA).

\section{Referências Bibliográficas}

AQUINO, L. P. C. T.; MACHADO, R. Z.; ALESSI, A. C.; SANTANA, A. E.; CASTRO, M. B.; MARQUES, L. C.; MALHEIROS, E. B. Hematological, biochemical and anatomopathological aspects of the experimental infection with Trypanosoma evansi in dogs. Arquivo Brasileiro de Medicina Veterinária e Zootecnia, Belo Horizonte, v. 54, n.1, p. 8-18, 2002.

BUSH, B. M. Interpretação de resultados laboratoriais para clínicos de pequenos animais. São Paulo: Roca, 2004.

CHOUDHURY, A ; MISKA, K. K. Experimental infection of T. evansi in the cat. Transactions of the Royal Society of Tropical Medicine and Hygiene, London, v. 66, n. 4, p. 672-673, 1972.

COLPO, C. B.; MONTEIRO, S. G.; STAINKI, D. R.; COLPO, T. B.; HENRIQUES, G. B. Infecção natural por Trypanosoma evansi em cães. Ciência Rural, Santa Maria, v. 35, n. 3, p. 717-719, 2005.
DA SILVA, A. S.; DOYLE, R. L.; MONTEIRO, S. G. Métodos de contenção e confecção de esfregaço sanguíneo para pesquisa de hemoparasitas em ratos e camundongos. Revista da Faculdade de Zootecnia, Veterinária e Agronomia, Uruguaiana, v. 13, n. 2, p. 8387, 2006.

DA SILVA, A. S.; COSTA, M. M.; LOPES, S. T. A.; MONTEIRO, S. G. Alterações hematológicas em coelhos infectados experimentalmente pelo Trypanosoma evansi. Ciência Rural, Santa Maria, v. 38, n. 2, p. 538-542, 2008.

DA SILVA, A. S.; ZANETTE, R. A.; WOLKMER, P.; COSTA, M. M.; GRESSLER, L. T.; FACCIO, L.; SANTURIO, J. M.; LOPES, S. T. A.; MONTEIRO, S. G. Trypanosoma evansi: hematologic changes in experimentally infected cats. Experimental Parasitology, London, v. 123, n. 1, p. 31-34, 2009.

DOYLE, R. L.; DA SILVA, A. S.; SANTURIO, J. M.; MONTEIRO, S. G.; GRAÇA, D. L. Eficácia de medicamentos no controle da infecção experimental por Trypanosoma evansi em ratos. Acta Scientiae Veterinariae, Porto Alegre, v. 35, n. 1, p. 67-71, 2007.

FELDMAN, B. V.; ZINKL, J. G.; JAIN, N.C. Schalm's veterinary hematology. Philadelphia: Lippincott Williams \& Wilkins, 2000. 1344p.

GUTIERREZ, C.; CORBERA, J. A.; JUSTE, M. C.; DORESTES, F.; MORALES, I. Clinical, hematological and biochemical findings in an outbreak of abortion and neonatal mortality associated with Trypanosoma evansi infection in dromedary camels. Annals of the New York Academy of Sciences, Nova York, v. 1081, n. 1, p. 325327, 2006.

HERRERA, H.M.; DAVILA, A.M.; NOREK, A.; ABREU, U.G.; SOUZA, S.S.; D ${ }^{\mathrm{a} A N D R E A, ~ P . S . ; ~}$ JANSEN, A.M. Enzootiology of Trypanosoma evansi in Pantanal, Brazil. Veterinary Parasitology, Amsterdam, v. 125, n. 3-4, p. 263-275, 2004.

HOARE, C. A. The Trypanosomes of mammals: a zoological monograph. Blackwell: Oxford, 1972, 749p.

JATKAR, P. R., PUROHIT, M. S. Pathogenesis of anemia in Trypanosoma evansi infection. I. Haematology. Indian Veterinary Journal, Chennai, v. 48, n. 2, p. 239-244, 1971.

KUBIAK, G. V. L.; MOLFI, A. Tripanosomíase eqüina (Mal das Cadeiras). Curitiba: Instituto de Biologia e Pesquisas Tecnológicas do Estado do Paraná. : Tip. João Haupt, 1954. 51p. (Boletim, n. 33.)

LUN, Z. R.; DESSER, S. S. Is the broad range of hosts and geographical distribution of Trypanosoma evansi 
attributable to the loss of maxicircle kinetoplast DNA? Parasitologia Today, v. 11, n. 4, p. 131-133, 1995.

MONZON, C. M.; MANCEBO, O. A.; ROUX, J. P. Comparison between six parasitological methods for diagnosis of Trypanosoma evansi in the subtropical area of Argentina. Veterinary Parasitology, Amsterdam, v. 36, n.1-2, p. 141-146, 1990.

MONZON, C. M .; VILLAVICENCIO, V. I.; ROUX, J. P. Estudios hematológicos en cobaios y equinos infectados con el Trypanosoma evansi (Steel,1885). Veterinaria Argentina, Buenos Aires, v. 8, n.3, p. 668-676, 1991.

MWANGI, S. M.; MCODIMBA, F.; LOGAN-HENFREY, L. The effect of Trypanosoma brucei brucei infection on rabbit plasma iron and zinc concentrations. Acta Tropica, Estocolmo, v. 59, n. 4, p. 283-291, 1995.

OLIVEIRA, T. C. G.; MENEGUIN, J. M.; PEREIRA, E. A. Comportamento do Trypanosoma evansi (T. equinum) em animais de laboratório. Arquivo Brasileiro de Veterinária e Zootecnia, Belo Horizonte, v. 41, n. 4, p. 271-277, 1989.

QUEIROZ, A. O.; LEGEY, A. P.; XAVIER, S. C. C.; JANSEN, A. M. Specific antibody levels and antigenic recognition of wistar rats inoculated with distincts isolates of Trypanosoma evansi. Memórias do Instituto Oswaldo Cruz, Rio de Janeiro, v. 96, n. 7, p. 965-967, 2001.

QUIÑONES, M. M. E.; FINOL, H. J.; TORRES, S. H. Muscular changes in Venezuelan wild horses infected with Trypanosoma evansi. Journal of Comparative Pathology, California, v. 110, n. 1, p. 79-89, 1994.

RODRIGUES, A.; FIGHERA, R. A.; SOUZA, T. M.; SCHILD, A. L.; SOARES, M. P.; MILANO, J.; BARROS, C. S. L. Outbreaks of trypanosomiasis in horses by Trypanosoma evansi in the state of Rio Grande do Sul, Brazil: epidemiological, clinical, hematological, and pathological aspects. Pesquisa Veterinária Brasileira, Rio de Janeiro, v. 25, n. 4, p. 239-249, 2005.

RUE, M. L. L.; SILVA, R. A. M. S.; CARLI, G. A. Leucocytes and reticulocytes counts in acute infection of dogs with Tripanosoma evansi (Steel, 1885) Balbani, 1888. Revista Latinoamericana de Microbiologia, México, v. 40, n. 4, p. 163-166, 2000.

SAKER, K. E. Nutricion and imune function. Veterinary Clinics of North America: Small Animal Practice, St. Louis, v. 36, n. 6, p. 1199-1224, 2006.

SILVA, R. A. M. S.; AROSEMENA, N. A. E.; HERRERA, H. M.; SAHIB, C. A.; FERREIRA M. S. Outbreak of trypanosomosis due to Trypanosoma evansi in horses of Pantanal Mato-grossense, Brazil. Veterinary Parasitology, Amsterdam, v. 60, n. 2, p. 167-171, 1995.

SILVA, F. A. S., AZEVEDO, C. A. V. Versão do programa computacional Assistat para o sistema operacional Windows. Revista Brasileira de Produtos Agroindustriais, Campina Grande, v. 4, n. 1, p. 71-78, 2002.

SILVA, R.A. M. S.; SEIDL, A.; RAMIREZ, L.; DÁVILA, A. M. R. Trypanosoma evansi e Trypanosoma vivax - biologia diagnóstico e controle, EMBRAPA. 2002. Disponível em: <www.cpap.embrapa.br/publicacoes/ online/Livro015>. Acesso em 15 jan. 2005.

UCHE, U. E.; JONES, T. W.; BOID, R. Antibody patterns in rabbits showing different levels of susceptibility to an experimental Trypanosoma evansi infection. Acta Tropica, Estocolmo, v. 52, n. 1, p. 139-147, 1992.

ZANETTE, R. A.; DA SILVA, A. S.; COSTA, M. M.; LOPES, S. T. A.; SANTURIO, J. M.; MONTEIRO, S. G. Ocorrência de Trypanosoma evansi em eqüinos no município de Cruz Alta - RS, Brasil. Ciência Rural, Santa Maria, v. 38, n. 5, p. 1468-1471, 2008. 
